\title{
JOVENS EVANGÉLICOS UNIVERSITÁRIOS: a ressignificação da crença e da prática religiosa
}

\author{
EVANGELICAL UNIVERSITY STUDENTS: \\ re-signification of religious belief and practice
}

\author{
Volney José Berkenbrock * \\ Karen Aquino Rangel da Costa $* *$
}

\begin{abstract}
RESUMO
O presente artigo tem como objetivo apresentar um aspecto das trajetórias religiosas de universitários evangélicos no Brasil: a ressignificação da crença e da prática religiosa. As considerações e análises apresentadas são parte de resultados de pesquisa realizada com universitários participantes de um movimento religioso estudantil conhecido como Aliança Bíblica Universitária do Brasil (ABUB). Os sentidos religiosos destes jovens parecem ser transformados à medida que a universidade coloca em evidência o pluralismo presente na sociedade brasileira e fortalece a necessidade de ressignificação de alguns pontos em suas crenças e práticas religiosas. $O$ processo de ressignificar pode levar a alguns movim entos na trajetória religiosa como o trânsito religioso, percurso entre diferentes opções religiosas, adesões provisórias, a produção de sínteses pessoais para a crença, assim como as negociações próprias em relação às práticas requeridas dos adeptos. Tais movimentos contribuem para mudanças significativas na religião tanto a nível individual quanto institucional.
\end{abstract}

Palavras-chave: Trajetória Religiosa. Universitários Evangélicos. Religiosidade Jovem.

\begin{abstract}
This paper aims to present an aspect of evangelical university student's religious trajectory in Brazil: the resignification of the belief and religious practice. The considerations and analyses presented are part of the results from a research carried out with participants of a religious student movement known as Aliança Bíblica Universitária (ABUB). The religious senses of these young students seems to be transformed as the university highlights the pluralism present in the Brazilian society and strengthens the necessity of resignification in some points of their beliefs and religious practices. The resignifying process can lead to some movements in the religious trajectory such as religious transit, movement among different religious options, provisional accessions, a production of personal syntheses for beliefs and own negotiations regarding to required practices from the adepts. These movements contribute to significant changes in religion both individually and institutionally.
\end{abstract}

Keywords: Religious Trajectory. Evangelical University Students. Young Religiosity.

\footnotetext{
* Doutor em Teologia pela Univ ersidade Federal de Bonn (Alemanha Rheinische-Friendrich-WilhelmUniversität). Atualmente é professor do Programa de Pós-graduação em Ciência da Religião da Universidade Federal de Juiz de Fora - MG. E-mail: volney @itf.org.br

** Mestra em Ciência da Religião e graduada em Serviço Social pela Universidade Federal de Juiz de Fora (UFJF). Atualmente é doutoranda do Programa de Pós-graduação em Ciência da Religião pela (UFJF). E-mail: karenaquinoangel@ hotmail.com
} 


\section{INTRODUÇÃO}

De acordo com Peter Berger (2012), os mundos são construídos e mantidos socialmente. Essa construção e manutenção pode se dar a partir da religião. Nos processos de socialização o indivíduo apreende os sentidos objetivados, se identifica com eles e é modelado por eles. "A relação dialética de perda de sentido e uma nova criação de sentido, ou seja, de enfraquecimento e fortalecimento de sentido, pode ser encontrada mais claramente no caso da religião" (BERGER; LUCKMANN, 2012, p. 43). Logo, a trajetória do sujeito religioso é marcada pela criação e fortalecimento de um sentido religioso que explica e mantém seu mundo socialmente construído, e tal mundo vai adquirindo novas gradações na medida em que se depara com novos sentidos nos processos de socialização, se identifica com eles e por eles pode ser modelado.

A pesquisa busca compreender a trajetória religiosa de jovens universitários evangélicos a partir de sua inserção no mundo universitário, sua experiência no movimento estudantil religioso e sua prática religiosa em instituição eclesial. Para tanto, torna-se relevante a análise dos sentidos adquiridos por eles no processo de continuidade da construção social de seu mundo durante sua vida acadêmica, onde sua religiosidade, considerando não somente as práticas religiosas como também as crenças em si, pode então ser mantida, transformada, ou ainda, abandonada.

Como recorte foi escolhido um dos grupos religiosos estudantis evangélicos que desenvolve suas atividades religiosas em universidades brasileiras, conhecido por Aliança Bíblica Universitária do Brasil (ABUB).

A ABUB se entende como uma organização missionária evangélica interdenominacional que atua através da iniciativa dos próprios estudantes. Tal organização existe no Brasil desde 1957 e faz parte de um movimento internacional: IFES (International Fellowship of Evangelical Students), uma comunidade global de estudantes evangélicos. ${ }^{1}$

A pesquisa realizada utilizou-se tanto da metodologia de observação participante, bem como de entrevistas semi-estruturadas. Dos muitos dados levantados, um aspecto que chamou a atenção foi o da ressignificação nas trajetórias

\footnotetext{
${ }^{1}$ Aliança Bíblica Universitária do Brasil. Disponível em <www.abub.org.br $>$. Acesso em: 20 de abril de 2016.
} 
religiosas dos estudantes da ABUB. Este texto irá apresentar justamente este aspecto da pesquisa, que se destacou na fala de muitos dos estudantes entrevistados: a ressignificação da crença e da prática na trajetória religiosa após o ingresso à universidade.

Em primeiro lugar, é necessário ressaltar que não é possível falar de uma trajetória religiosa comum aos jovens universitários. Ainda que alguns padrões possam ser reconhecidos e deles se inferir algumas generalizações feitas a partir de dados coletados empiricamente, é imprescindível que a interpretação destes leve em consideração que lidamos com trajetórias religiosas diversas.

A diversidade de trajetórias encontradas e suas particularidades não são percebidas através de pesquisas demográficas. Tais investigações são importantes para indicar através das estatísticas, categorias que se destacam e podem ser exploradas dentro da temática, além de estabelecer alguns parâmetros que contribuem para refletir de maneira mais abrangente sobre o objeto estudado. No entanto, pela exigência de definições precisas, as abordagens quantitativas acabam por captar apenas determinado momento da trajetória do indivíduo, dificultando assim a observação de situações que são presentes na vivência religiosa dos jovens universitários, como o percurso entre diferentes opções religiosas, o trânsito religioso, as adesões provisórias, a produção de sínteses pessoais para a crença, assim como as negociações próprias em relação às práticas requeridas dos adeptos.

Esses movimentos podem ocorrer durante a trajetória religiosa do indivíduo e são movimentos comuns à condição moderna.

Num primeiro momento, apresentaremos a metodologia utilizada na realização da pesquisa e alguns pontos importantes para a compreensão do estudo desenvolvido. Em seguida, faremos uma reflexão sobre esta condição moderna em que se encontra o jovem universitário. A partir desta realidade apresentaremos o aspecto da ressignificação da crença e prática religiosa, aparentemente presente em trajetórias de estudantes do grupo pesquisado.

\section{A PESQUISA}

A pesquisa foi realizada utilizando-se da metodologia qualitativa de investigação social. A escolha por este método é por entender que os estudantes 
possuem um conhecimento, uma compreensão de mundo que pode ter sido construída a partir da religião e acrescida de novos sentidos adquiridos na trajetória acadêmica, e que este conhecimento tem uma lógica e se relaciona com outros conhecimentos. Para tanto, a pesquisa qualitativa é ideal pois pretende, "usando, ou não, quantificações, interpretar o sentido do evento a partir do significado que as pessoas atribuem ao que falam e fazem" (CHIZZOTI, 2006, p. 28).

Foi realizada observação participante em encontros promovidos pela organização nos anos de 2016 e 2017 em âmbito nacional e no estado de Minas Gerais. Em um dos encontros nacionais, realizado em janeiro de 2017 em Vila Velha, Espírito Santo, foram entrevistados dez estudantes engajados na ABUB em diferentes regiões do país.

Anualmente a organização promove este encontro de formação para seus membros e como requisito para inscrição no evento cada participante deve enviar uma carta de motivação e um histórico de sua trajetória tanto na igreja como na própria organização. Com o objetivo de definir a amostra de entrevistados, foi feita a leitura prévia do material enviado por todos os participantes inscritos. As cartas também foram utilizadas como material para a análise da trajetória religiosa. Dos 75 inscritos no evento, 56 autorizaram o uso de suas cartas para fins de pesquisa.

A amostra utilizada é de caráter não-probabilístico, considerando que tanto a coleta dos dados como a análise dos mesmos têm como base o método qualitativo de pesquisa. Como salienta Pires (2010, p.154), "é próprio da pesquisa qualitativa ser flexível e descobrir-construir seus objetos à medida que a pesquisa progride”.

Em torno do tema trabalhado na pesquisa, há um universo geral constituído por jovens universitários evangélicos, e dentro deste, o universo de análise aqui escolhido: jovens participantes da ABUB. Ainda que se trate de uma amostra nãoprobabilística, elencamos critérios aos tipos de dados a serem coletados a partir de uma caracterização da "amostragem por casos múltiplos" e a construção de uma “amostra por homogeneização" (PIRES, 2010, p. 194).

As pesquisas que se utilizam de uma amostragem por casos múltiplos, se interessam pelas experiências de vida, pelas instituições e pelas práticas sociais. Neste sentido, cada indivíduo dentro do grupo a ser entrevistado é necessário para a obtenção de algumas informações sobre o objeto. Trata-se, assim, de "conhecer seu ponto de vista sobre o desenvolvimento dos fatos ou o funcionamento de uma 
instituição ou de apreendê-lo através de sua própria experiência; de dar conta de seus sentimentos e percepções sobre uma experiência vivida" (PIRES, 2010, p. 194).

A opção pela amostra por homogeneização se dá pela característica dos universitários entrevistados. Trata-se de um grupo relativamente homogêneo, por referir-se a jovens que fazem parte de um grupo religioso afim e, portanto, estão em um meio social que lhes é relativamente comum. Utiliza-se neste caso o princípio da diversificação interna, a escolha de informantes dos mais diversos possíveis no grupo. Por isso, além das variáveis gerais (sexo, idade, classe social, etc.), temos as variáveis específicas que podem contar mais neste caso, por serem particulares ao universo geral da pesquisa, e também por relacionar-se aos problemas a serem investigados. São elas: 1- tradição religiosa da família (estudantes oriundos de famílias que aderem à tradição evangélica ou não); 2- diversidade de trajetórias religiosas.

Sobre a primeira, Danièle Hervieu-Léger (2008), tratando do tema da crise da transmissão de valores religiosos de uma geração a outra, acentua que a relação entre pais e filhos, ou ainda de membros de uma família, faz referência a um modelo de socialização que localiza um transmissor ativo, detentor de um patrimônio de saberes e de referências religiosas que se esforça, com maior ou menor sucesso, para transmiti-los ao destinatário da transmissão. "Os dados recolhidos [em algumas pesquisas dedicadas ao tema] revelam claramente as dificuldades da operação, num universo cultural onde toda proposição religiosa é confrontada a uma multiplicidade de ofertas simbólicas variadas”. (HERVIEU-LÉGER, 2008, p. 59). Sendo assim, é necessário considerar a tradição religiosa familiar, a igreja de origem e a trajetória religiosa do estudante antes de chegar à vida universitária. Desta forma pode-se compreender com mais clareza as possíveis crises de sentido do jovem na condição de universitário.

Sobre a segunda variável, considerando que a pesquisa tem como objetivo a compreensão da trajetória religiosa do jovem universitário, buscamos entrevistar dentro de um grupo específico - universitários participantes da ABUB - casos múltiplos que sejam os mais diversos possíveis em relação à trajetória religiosa. 


\title{
3 A CONDIÇÃO MODERNA: O PLURALISMO COMO REALIDADE EVIDENTE
}

Os pressupostos da Modernidade contribuíram para a construção de uma dicotomia existente entre o conhecimento religioso e o conhecimento científico, pautado na razão, e para a valorização da cientificidade - anunciando como hegemônicas as maneiras desencantadas de explicar o mundo, sem o auxílio da magia e do sobrenatural. A construção deste novo modelo de sociedade teve seu ápice no século XIX, com a ascensão da burguesia e o desenvolvimento de arranjos sóciopolíticos que deram vida a novas formas de organização do sistema produtivo e das relações sociais. Com a Revolução Industrial o estilo de vida campesino dá espaço à vida operária, que transforma o campo político e econômico. Na perspectiva filosófica, o Iluminismo funda a criação da figura do indivíduo e o racionalismo cartesiano propõe uma interpretação do mundo com base na razão e no método científico.

\begin{abstract}
A Modernidade se caracteriza pela colocação do indivíduo como medida e como fim. O ser humano, em sua individualidade e racionalidade, de certa forma substitui o centro anterior, a saber, um cosmo sagrado, com suas derivações encompassadoras de sentido e norma, gerido por instituições religiosas que davam a coesão social e cultural e que alocavam o centro de sentido para além do ser humano. A Modernidade, no entanto, coloca o ser humano como medida de si, de suas relações e do universo, a partir de uma lógica cartesiana e de uma moral kantiana. Já não seria mais o cimento da coesão cultural-social ditado pela religião o que daria o sentido ordenador da realidade e do social, com suas mediações, mas doravante a própria racionalidade, a própria independência de escolha racional centrada no indivíduo autônomo (PORTELLA, 2006, p. 72).
\end{abstract}

Sendo assim, a época moderna e as transformações associadas a ela modificaram a concepção de sujeito, que se torna um sujeito individualizado. Aquele que anteriormente tinha seus apoios estáveis nas tradições, na modernidade passa a ser um indivíduo soberano, que é livre para pensar fora de uma lógica divinamente estabelecida.

Para Danièle Hervieu-Léger (2008), a racionalidade no mundo moderno foi colocada à frente em todos os domínios da ação. No plano das relações sociais isso significa que o ser humano adquire autonomia para construir ele mesmo significações que dão sentido à própria existência, não necessitando mais se amparar na tradição. 
E "no âmbito da explicação do mundo e dos fenômenos naturais, sociais ou psíquicos, a racionalidade moderna exige que todas as afirmações explicativas respondam a critérios precisos de pensamento científico” (HERVIEU-LÉGER, 2008, p. 31).

No campo da religião observaram-se transformações profundas - tanto no âmbito da crença quanto das instituições - que levaram ao seu enfraquecimento social e cultural. Logo, nas sociedades modernas a crença e a prática religiosa passam a fazer parte da esfera privada, se tornando cada vez menos submetidas às instituições religiosas.

A Modernidade dá espaço ao que chamamos de secularização, fenômeno que foi, e ainda é, amplamente discutido nas ciências sociais e nos estudos voltados para a religião. As teorias desenvolvidas em torno do tema, que por vezes são cunhadas com base na tese weberiana sobre o desencantamento do mundo, são muitas. De início pensou-se que a religião desapareceria à medida que a secularização avançasse. Porém, posteriormente observou-se que a religião ainda dava sinais de progresso, ainda que de maneira diferenciada. Danièle Hervieu-Léger (2008) destaca que a secularização não é a perda da religião no mundo moderno, "é o conjunto dos processos de reconfiguração das crenças que se produzem em uma sociedade onde o motor é a não satisfação das expectativas que ela suscita, e onde a condição cotidiana é a incerteza ligada à busca interminável de meios de satisfazê-las” (HERVIEULÉGER, 2008, p. 41).

Entre diferentes concepções do que seria e para onde vai a secularização, Charles Taylor (2010) aponta para uma característica, um modo de secularidade, promovido pela “Era Secular” como ele denomina. Seu argumento principal é que a secularidade de uma sociedade não pode ser definida apenas pela existência de espaços públicos secularizados ou pelo declínio da crença e da prática religiosa. Existe um terceiro sentido da secularidade que precisa ser considerado - as condições de crença. Segundo Taylor (2010, p. 15), houve uma mudança que levou uma sociedade na qual era praticamente impossível não acreditar em Deus para uma na qual a fé, até mesmo para o crente mais devoto, representa uma possibilidade humana entre outras, inclusive entre a possibilidade da descrença. A fé em Deus numa era secular não é mais axiomática e, portanto, pode ser que para alguns seja difícil conservá-la. Desse modo, Taylor assume que uma era ou sociedade seria secular ou não em virtude das condições da experiência do espiritual e da sua busca; e sustenta que no 
caso ocidental, a mudança para a secularidade pública contribuiu em parte para promover uma Era Secular no que diz respeito às condições de fé.

Certamente faz-se necessário problematizar os processos de secularização no Brasil. Taylor deixa claro que sua descrição e explicação é desenvolvida a partir da realidade ocidental, mais especificamente, o mundo do Atlântico Norte, e que o fenômeno da secularização existe para além deste mundo, porém, com expressões e exigências distintas em cada civilização. "Essas transformações cruciais precisam ser estudadas em seus diferentes locais civilizacionais antes de nos precipitarmos em generalizações globais" (TAYLOR, 2010, p. 36). Pensando na realidade do processo de secularização no Brasil, pode-se inferir que ele não acontece da mesma forma em todos os setores da sociedade e é perpassado por diversas variáveis. Não podemos afirmar que não vivemos numa sociedade secularizada, tampouco, que não nutrimos mais uma perspectiva religiosa nos espaços públicos. No entanto, podemos dizer que em determinados ambientes uma lógica secular, no sentido de Taylor quanto às condições para a fé, pode ser encontrada de maneira mais explícita - como na universidade.

Peter Berger, sociólogo da religião, também se dedicou a elaborar uma teoria da secularização. No entanto, em sua última obra, Berger (2017) vai rever sua posição no que tange à secularização, compreendendo após uma reflexão de longos anos observando a evidência empírica, que a modernidade não acarreta necessariamente um declínio da religião e que o pluralismo não é apenas um dos fatores que sustentam a secularização; “de fato, o pluralismo, a coexistência de diferentes cosmovisões e sistemas de valores na mesma sociedade, é a maior mudança provocada pela modernidade em relação ao lugar da religião, tanto nas mentes dos indivíduos quanto na ordem institucional” (BERGER, 2017, p. 10). O estudioso chegou a essa conclusão através de algumas experiências nas quais pôde observar a expansão da religião no Terceiro Mundo, na América Latina, Ásia e África e a existência de uma religiosidade difusa nestes locais.

Presumindo que a ciência é tida como a causa principal da secularização, Berger entendia que a compreensão científica da realidade supostamente marginaliza a religião e acaba tornando-a inconcebível. Entretanto, ainda que a maioria das pessoas modernas sejam afetadas pela revolução tecnológica que a ciência provocou, o raciocínio científico não domina a maneira como elas pensam na vida ordinária. 
Nesta linha de pensamento, Berger relata (2017, p. 52) que partia do pressuposto de que "alguns dos processos básicos da modernidade - industrialização, urbanização, migração, educação - expulsavam a religião de grande parte da ordem institucional”. Também tinha a concepção de que o pluralismo igualmente alimentava a secularização. Contudo, Berger percebeu um erro em sua forma de compreender as consequências da modernidade para a religião ao assimilar que "o pluralismo enfraquece a certeza religiosa e abre uma plenitude de escolhas cognitivas e normativas. Em grande parte do mundo, contudo, muitas destas escolhas são religiosas” (BERGER, 2017, p. 52).

No mundo moderno, o pluralismo se tornou onipresente. A modernidade não leva necessariamente à secularização; onde isto ocorre, esta evolução não pode ser suposta, mas deve antes ser explicada. A modernidade leva necessariamente ao pluralismo. Ela na verdade coloca a fé diante de um desafio significativo, mas este é diferente do desafio da secularização (BERGER, 2017, p.53).

Sendo assim, Berger assume que a teoria da secularização foi um paradigma para sua época e agora reivindica-se um novo paradigma, para o qual ele mesmo procura contribuir fazendo alguns apontamentos iniciais.

O pluralismo, como ele enfatiza, mais do que um conceito ou um fenômeno na mente do pensador, é um fato empírico na sociedade experimentado por pessoas comuns, que para ele pode ser definido de maneira simples como "uma situação social na qual pessoas de diferentes etnias, cosmovisões e moralidades vivem juntas pacificamente e interagem amigavelmente" (BERGER, 2017, p. 20).

Em quase todas as sociedades existiram formas de pluralismo, no sentido da existência de diferentes formas de vida numa mesma sociedade. Não se pode dizer que é uma nova característica na história da humanidade em termos de existência, no entanto a relação do ser humano com tal fenômeno é que se modifica, é marcada pela convivência em espaços diversificados, por formas culturais, visões de mundo, opções religiosas diferentes e outros. Portanto, pode-se observar que na forma moderna de pluralismo as diferentes ordens coexistentes e muitas vezes também concorrentes, visto que a convivência nem sempre é pacífica, são elucidadas.

Esta coexistência de cosmovisões e sistemas de valores diferentes numa mesma sociedade se torna um desafio para todas as tradições religiosas, porque pouco sentido faz falar de pluralismo quando não há interação. "Para que o 
pluralismo desencadeie a sua plena dinâmica, deve haver conversação constante, não necessariamente entre iguais, mas prolongada no tempo e cobrindo uma ampla variedade de temas" (BERGER, 2017, p. 20). Neste contexto, o que acontece é um processo chamado por Berger (2017) de "contaminação cognitiva", que diz respeito ao fato de que as pessoas convivendo influenciam umas às outras.

A contaminação cognitiva num contexto de pluralismo é uma condição permanente e gera uma relativização ocorrida quando alguém se comporta de maneira diferenciada daquilo que o outro aceitava normalmente como comportamento apropriado. "A relativização se intensifica se o desafiador verbalizar o desacordo. Assim, as várias formas de interação com diferentes cosmovisões e com os comportamentos que elas engendram iniciam um processo de relativização" (BERGER, 2017, p. 23). Ela é uma compreensão de que a realidade pode ser percebida e vivenciada de uma forma diferente daquela que pensávamos ser a única possível. A partir dela, muitas das certezas com as quais os seres humanos costumavam viver são enfraquecidas.

Portanto, enquanto o pluralismo fomenta a coexistência pacífica de diferentes formas de vida e de ordens de valores, ele não se destina a agir contra a difusão de crises de sentido. Berger trabalhou o tema da crise de sentidos na modernidade em um livro anterior e destacou que as virtudes do pluralismo "dizem ao indivíduo como se comportar em relação aos outros, isto é, pessoas e grupos diferentes dele em seu projeto de vida. Mas não lhe dizem como deve levar bem concretamente a própria vida, quando a validade inquestionável das ordens tradicionais for abalada" (BERGER; LUCKMANN, 2012, p. 40). Sendo assim, a forma moderna de pluralismo é também razão para a difusão de crises subjetivas e intersubjetivas de sentido.

\section{A RESSIGNifiCAÇÃo dA CRENÇA E DA PRÁTICA RELIGIOSA}

Ainda que as trajetórias religiosas dos estudantes sejam diversas, é possível apontar um denominador comum: todos se encontram na universidade. Tornar-se um universitário, independente da trajetória vivenciada até então, significa ingressar numa nova realidade, num submundo, onde novos sentidos são oferecidos por meio de mais um processo de socialização secundária, visto que estes são infindáveis. 
A universidade, como transmissora e geradora de conhecimentos, proporciona o acesso a outros mundos, envolve pessoas de diversas regiões do país, pois o fluxo de estudantes que mudam de cidade para estudar é grande. Toda essa heterogeneidade cria um campo fértil para a proliferação de culturas, hábitos, práticas sociais, saberes, lazeres e religiosidades. Sendo assim, o estudante passa a ter contato com realidades que talvez desconhecesse, pode agora conhecer e constatar a existência de diferentes concepções de mundo com mais clareza. Não podemos afirmar que a consciência deste mundo de diferentes referências não existia anteriormente. No entanto, o pluralismo presente na sociedade se torna mais evidente e tematizado para ele na universidade, tanto pelo ambiente culturalmente plural, como pelo período que se mantém ali - em média cinco anos - o que torna possível a construção de relações estáveis e duradouras.

Neste contexto, e diante das crises de sentido que podem ser difundidas pela realidade do pluralismo, muitos jovens universitários do grupo estudado ressignificam suas crenças. Essa ressignificação afeta a trajetória, pois muda não somente a interpretação de mundo, antes muitas vezes prioritariamente construída por sentidos religiosos, mas também as práticas religiosas.

$\mathrm{Na}$ pesquisa realizada assumimos que os estudantes pesquisados no momento da pesquisa são jovens que mantêm suas crenças e práticas religiosas. Existem outros estudantes que em sua trajetória podem ter abandonado os sentidos religiosos e passado a viver majoritariamente com base no discurso secular. No entanto, os jovens participantes da ABUB querem e procuram manter sua fé durante o período acadêmico, seu engajamento no movimento visa também seu convívio com pessoas da mesma fé, o que acaba por fortalecer os sentidos religiosos na maioria dos casos. Porém, o que queremos apontar são as transformações necessárias para esta manutenção através de ressignificações, rearranjos, concessões e relativizações. Escolhemos a palavra ressignificação para expressar estes processos, pois ela revela o que identificamos nos dados coletados, nas falas dos estudantes: o enfraquecimento e/ou fortalecimento de algumas significações atribuídas aos sentidos e práticas religiosas construídas anteriormente ao período acadêmico, ou ainda elaborações de outros sentidos e práticas.

Os estudantes de áreas das ciências humanas, sociais aplicadas e artes parecem ter mais necessidade de ressignificar seus sentidos religiosos para que o mundo 
construído socialmente continue coerente com a fé e a prática religiosa. No relato abaixo, de uma estudante de Ciências Sociais, percebemos que o argumento religioso para a explicação da existência de Deus construído por ela antes de seu ingresso na universidade se enfraqueceu à medida que os conteúdos apreendidos na faculdade a faziam refletir sobre as construções sociais a partir de outra perspectiva, e a ela foi preciso encontrar outros motivos para a existência de Deus, outros significados para sua fé nele.

Quando eu entrei na faculdade eu entrei para um curso que me fez ter uma visão muito diferente das minhas verdades. Antes de eu entrar na faculdade, eu achava que Deus existia pelas coisas que eu sentia, do tipo, sentir a presença dele, sentir ele falando comigo, sentir ele através das músicas, das coisas que as pessoas falam. Eu achava que a existência dele se dava nisso, no que eu sentia. E aí, quando a gente estuda um pouco a antropologia e a sociologia, a gente vê que a gente é muito produto do que acontece durante a nossa vida. Eu olho para mim hoje, pra coisas pequenas, tipo, uma antropologia básica dos sentidos, o que você acha engraçado, o que você acha triste, o que você acha dramático... Todas essas coisas são produtos de uma série de vivências que eu trouxe através da minha vida. E eu comecei a achar que esse argumento é muito fraco pra mim e para a maioria das pessoas que não acreditam em Deus e que me questionam isso. E aí eu comecei a tentar buscar outros motivos para a existência de Deus, para minha permanência na fé. (Helena)

Já os estudantes de áreas das ciências exatas, biológicas e engenharias, relataram não vivenciar tantas crises em relação a sua fé no que diz respeito aos conteúdos aprendidos no curso. Afirmam que os fatores que às vezes dificultam a manutenção da fé são de ordem mais prática, relacionados ao comportamento dos amigos que não professam a mesma fé e têm uma conduta diferente.

Como tem em outros cursos, eu vejo relatos de outros cristãos, de serem bem pressionados com relação a fé. Na minha faculdade eu acho que seria mais em relação ao comportamento, a influência de amizades, por exemplo, de sei lá... de talvez ir para festas, bebedeiras, essas coisas e tal, coisa mais... É mais um desvio de comportamento, de práticas, não a nível intelectual, porque no curso [na medicina] a gente não chega a ponto de questionar. A gente fica muito naquela coisa assim já estabelecida, você não tem muito o que imaginar ou pensar, é a doença ali e pronto, não tem muita coisa por trás, envolvendo acho que filosofia ou alguma coisa assim. (Joana).

Percebemos que este enfraquecimento dos sentidos religiosos se dá a partir do contato com o outro, com o diferente, seja pela convivência com discursos seculares, no caso dos estudantes nas áreas das ciências humanas, sociais aplicadas ou artes, ou pela "influência de amizades", como exposto no relato acima, pelo contato com 
comportamentos diferenciados, no caso dos estudantes de ciências exatas, biológicas e engenharias.

Como apontou Berger (2017) acerca da contaminação cognitiva, através da convivência, da interação com diferentes cosmovisões e comportamentos, a relativização pode surgir. As certezas são enfraquecidas e crises de sentido podem aparecer, fazendo assim oportunas as ressignificações.

É interessante destacar que as ressignificações não são feitas apenas a partir do contato com pessoas de outras tradições religiosas ou sem religião e de conteúdos seculares. O questionamento em relação a alguma crença ou prática religiosa pode surgir também pela convivência com discursos religiosos de outras denominações evangélicas, já que a ABUB proporciona aos estudantes este contato, por ser um movimento evangélico interdenominacional. Todos os entrevistados que atualmente estudam em áreas do conhecimento como ciências exatas, biológicas e engenharias relataram que as crises em relação a fé não surgiram pelo conteúdo da faculdade, como expusemos acima, mas enfatizaram que algumas crises e questionamentos em sua trajetória foram em relação a algumas práticas e elementos específicos de sua tradição religiosa - crises estas que foram impulsionadas pelo contato com pessoas de diferentes denominações, que tratam os mesmos assuntos de formas divergentes.

O próximo relato diz respeito a um estudante de engenharia. Podemos notar como a ressignificação de seu entendimento sobre a tradição evangélica mudou não somente sua trajetória religiosa, mas a de toda sua família.

O meu irmão conheceu a ABU em 2011 e a ABU é um movimento que envolve várias denominações, gente de tudo quanto é lugar. $\mathrm{E}$ isso começou a fazer com que ele abrisse a cabeça para muita coisa. E ele começou a passar isso lá para casa. Tipo, na minha igreja não podia nem bater palma, sabe? $\mathrm{E}$ aí ele começou a falar da $\mathrm{ABU}$, de outras pessoas e tal, de outras igrejas e a gente começou a abrir nossa cabeça. Mas o pastor dessa igreja, ele odiava a ABU, ele achava errado a gente se envolver com outras igrejas, com outras pessoas que não fossem da nossa igreja. E aí começou a ficar incompatível, a gente não conseguia mais concordar com o que ele falava no púlpito. E ele não gostava da $\mathrm{ABU}$ de jeito nenhum. A gente tentava estabelecer um diálogo com ele e ele não queria abrir a cabeça, então a gente não conseguia mais ficar lá. Então ficou insustentável, a gente tentou, eu sofri muito, todo mundo da minha família, porque 14 anos num lugar é muito tempo e a gente amava muito os irmãos de lá. E aí a gente começou a ver que não dava mais por uma série de motivos. Minha mãe já não estava mais conseguindo aceitar as coisas que aconteciam lá, e a gente tentou, tentou, mas não deu certo. A gente resolveu trocar por uma outra igreja. (Márcia). 
Esta transição de igreja após a mudança de pensamento sobre determinadas práticas antes tomadas como certas no caso acima, aparece como algo comum entre os estudantes. O trânsito religioso aparenta ser um movimento em resposta às ressignificações feitas. Na situação acima, os efeitos não foram apenas individuais, pois a família toda foi afetada pela atitude do irmão da estudante em compartilhar suas inquietações e discordâncias acerca das práticas costumeiras da igreja, que foram suscitadas por sua convivência com pessoas de outras igrejas que também participavam da ABU. Tal experiência parece não ter sido vivenciada pela família anteriormente, já que na igreja da qual eram membros "se envolver com outras igrejas" não era algo comum e era abordado pelo pastor, visto como autoridade na instituição, como algo errado.

A relativização advinda da contaminação cognitiva, própria do pluralismo, traz impactos tanto para os crentes individualmente que passam a relativizar o que creem, como para aqueles que convivem com eles, e até mesmo para as instituições religiosas que precisam ser modificadas para atender às novas demandas colocadas pelos fiéis se querem permanecer como estruturas de plausibilidade para a manutenção da fé.

Um evento que nos aproxima dessa realidade foi comentado por dois estudantes, ambos insatisfeitos com suas igrejas, e narrado com mais detalhes por um deles:

Aos 19 anos, ao ingressar no curso superior, tamanha a demanda de estudos, comecei a sentir um crescente desinteresse pela igreja que eu frequentava. Assim, me desliguei das atividades que participava na minha igreja e comecei apenas a frequentar os cultos. Isso aconteceu pelo fato de ter novos questionamentos, que vieram com o curso superior em Relações Internacionais. No ambiente que eu me encontrava, não havia muito espaço para tais questionamentos, naturais na vida de qualquer jovem, principalm ente ao entrar no ambiente da Universidade. Percebi que a igreja estava mais preocupada com a manutenção do status quo e não abria espaço para o diálogo. $\mathrm{E}$ eu ardia por uma fé que crescesse, que visse coisas novas, que mostrasse outras facetas do amor de Deus. Assim, quando eu decidi não frequentar mais aquela igreja, surge na minha cidade uma igreja orgânica de pessoas que deixaram outras comunidades de fé por acreditarem, entre outras coisas, que suas igrejas estavam sendo negligentes com a sociedade, algo que era inconciliável. Assim, faltando exatamente um mês para os meus 21 anos, comecei a frequentar uma igreja orgânica, da qual faço parte até hoje. Lá, conheci alguns membros ativos da ABU, onde conheci o movimento e comecei a me envolver um ano mais tarde. A igreja não é institucionalizada, entretanto, possuímos uma ONG para viabilizar projetos sociais. (Gisele). 
Neste relato fica claro o que Berger (2017) também sinaliza como efeito do pluralismo nas instituições religiosas - o processo de desinstitucionalização, pelo qual a objetividade das instituições é desfeita. Em seu entendimento, a instituição de modo geral é um "programa de comportamento, que quando adequadamente interiorizado, faz o indivíduo agir espontaneamente e sem muita ou nenhuma reflexão no setor relevante da vida social” (BERGER, 2017, p. 77). Além disso, a instituição pode ser descrita por objetividade. "No processo de desinstitucionalização, esta objetividade é desmantelada e se torna subjetivizada” (BERGER, 2017, p. 78).

No caso das instituições religiosas, pode-se dizer que elas regulam o comportamento do indivíduo na prática religiosa até que ele se torne habitual, normal, naturalizado, isento de questionamentos. Ou seja, a objetividade das instituições é transposta para a consciência. Isto, naturalmente, é a primeira coisa que acontece na infância. A instituição das maneiras adequadas de se portar diante do mundo se torna objetiva, é dada como certa na mente da própria criança. No pluralismo esta objetividade é abalada e subjetivizada.

A estudante do relato acima declarou seu desinteresse pela igreja ao ver que esta não correspondia às suas necessidades pessoais, não respondia aos questionamentos que surgiram com o curso superior, não abria espaço para diálogo e não a levava a sério a responsabilidade com a sociedade. Portanto, ao invés de se adequar à objetividade da instituição religiosa, em sua interpretação a instituição é que deveria se adequar à sua subjetividade, atendendo suas necessidades e proporcionando um espaço em que seus questionamentos pudessem ser acolhidos. Diante desta realidade, que era comum a outras pessoas da mesma cidade, criou-se uma comunidade "não institucionalizada”.

Em outro momento da entrevista, a mesma estudante descreveu esta comunidade que frequenta como sendo um grupo majoritariamente composto por estudantes universitários. A única pessoa que não é estudante é o líder, que é um professor. Sendo um grupo praticamente homogêneo entre si e que possui rotinas parecidas e interesses comuns, os membros decidiram que as atividades religiosas seriam realizadas apenas uma vez por semana, considerando a agenda cheia de um estudante. O formato do culto é diferente de outras igrejas, tendo como foco o estudo bíblico, porque se difere da pregação ao dar espaço para discussão, onde todos podem 
expor suas opiniões. É uma comunidade, portanto, que está organizada para atender as exigências colocadas pelos indivíduos que dela fazem parte.

Hervieu-Léger (2008) ao se perguntar como se formam as identidades religiosas num contexto moderno, procura compreender o tema a partir da perspectiva de uma modernidade religiosa caracterizada pela mobilidade. Ao que tudo indica à medida em que a desregulação da crença aparece como uma realidade inevitável, a mesma favorece a circulação dos crentes em busca de uma identidade religiosa que eles pensem ser mais adequada à sua forma de vivenciar a fé. Ela explica essa dinâmica através de duas figuras religiosas emblemáticas: o peregrino e o convertido.

Tanto pela figura do peregrino como pela do convertido, observa-se uma religiosidade centrada no indivíduo e sua realização pessoal. Segundo Ribeiro (2004, p. 89) a "nova liberdade religiosa incorpora duas tendências centrais na cultura secular: a individualização (cada indivíduo elabora um sistema próprio de crenças) e a subjetivação (o campo privilegiado das crenças é a experiência pessoal)”.

Este movimento não implica o fim das comunidades religiosas, pois a privatização da crença não desfaz a necessidade dos indivíduos de expressá-la em um grupo no qual eles encontram confirmação para a mesma, como se observou no acontecimento referido acima, em que um grupo de estudantes inconformados com as igrejas das quais faziam parte, criaram uma nova forma de expressar sua crença em um grupo no qual eles poderiam compartilhar a mesma visão e ter suas necessidades atendidas.

Em matéria religiosa, como em tudo o mais na vida social, o desenvolvimento do processo de pulverização individualista produz paradoxalmente a multiplicação de pequenas comunidades fundadas nas afinidades sociais, culturais e espirituais de seus membros. Tais comunidades subsistem, no campo da afetividade e da comunicação, aquelas comunidades "naturais" nas quais se tinha, outrora, um imaginário em comum. Na medida em que a representação da continuidade e da solidariedade do grupo não é mais vivida no dia-a-dia na família, no trabalho, na comunidade da vizinhança, no grupo confessional, ela surge, necessariamente, no interesse voluntário e pessoal dos indivíduos (HERVIEU-LÉGER, 2008, p. 51).

Isto não significa que as instituições religiosas desapareceram, ou ainda, que não tenham mais a capacidade de contribuir na formação das identidades religiosas. O pertencimento pode se manter, institucionalmente ou sob novas formas. A hipótese 
da socióloga Daniele Hervieu-Léger, é que as instituições religiosas, nesta conjuntura de crescimento da mobilidade entre os crentes e de expansão de uma religiosidade individual, sobre a qual sua influência é diminuída, "procuram canalizar e orientar inventando, por si mesmas, formas de uma sociabilidade religiosa peregrina, que esperam que se ajustem melhor às necessidades espirituais contemporâneas do que às assembleias clássicas dos praticantes" (HERVIEU-LÉGER, 2008, p. 100).

Um outro ponto também notável na questão da identidade religiosa é que a instituição propicia uma identidade ao indivíduo e em certo grau media sua relação com a religião. No entanto, o que pode ser percebido em algumas trajetórias religiosas dos estudantes, é que eles continuam aderindo a uma identidade pautada na relação com a instituição religiosa, mas escolhem o conteúdo desta adesão. Ainda que tenha ocorrido um processo de conversão, que reorienta os sentidos e provoca uma reinterpretação do mundo, pode-se perceber uma iniciativa individual de construir uma cosmovisão de fé própria, que não necessariamente segue os padrões estabelecidos pela instituição religiosa que lhe oferece a identidade professada. Neste caso, para o jovem universitário em questão, professar ser de uma igreja ou denominação não significa que a identidade que lhe é dada nesta relação determina o conteúdo daquilo que se acredita e pratica.

Podemos pensar nesta situação que uma das estudantes entrevistadas vive e compartilha. Ela se mudou de cidade para estudar e não encontrou uma igreja de sua denominação. Por se sentir acolhida em uma igreja de outra denominação, ela decidiu fazer parte daquela comunidade da qual não concorda com tudo em termos de comportamentos esperados e pressupostos teológicos. Mesmo apontando a identidade dessa igreja, quando precisa dizer de qual igreja faz parte, ela não adere por completo ao que se ensina ali, mantém sua forma de pensar e as doutrinas que acredita, como se percebe em sua fala:

Essa questão calvinista da predestinação, eu completamente discordo, e ele [o pastor] está tentando enfiar aquilo goela abaixo da gente como se aquilo fosse certo. Discordo. Eu tenho o direito de discordar, eu tenho direito de achar que beber não é errado, eu tenho direito de achar.... Daí ele diz: a gente está aqui reunindo todo mundo enquanto as pessoas estão lá fora estão em balada e em festa. Daí a minha amiga falou: mas eu vou em festa, vou em balada, qual é o problema? (Bruna) 
Formas de pensar expressas em afirmações como "eu tenho o direito de discordar" nos levam a refletir sobre a construção da identidade religiosa desta estudante, que embora faça parte de uma igreja, não concorda com tudo que ela propaga, afinal sua identidade não está limitada e unificada à apenas uma estrutura. Sendo assim, construir sua identidade direcionada a uma única direção, identificando-se e projetando-se em uma instituição, pode parecer algo um tanto forçado, como podemos perceber no sentimento dela ao compreender que certo conteúdo está sendo "enfiado goela abaixo". Aqui, fica clara a interpretação que a estudante faz sobre as negociações próprias em relação às práticas requeridas dos adeptos, como não beber e não ir à balada. Ela compreende as negociações com naturalidade, como algo que pode ser feito a qualquer momento.

Outra estudante afirma sua identidade cristã juntamente com sua identidade feminista. Ela relata a primeira vez que participou da reunião de um coletivo no qual atualmente exerce sua militância:

E quando eu fui na reunião do coletivo Olga Benário, que é um grupo de mulheres socialistas, era bem na época do 8 de março, estava tendo um monte de eventos sobre a mulher e eu gosto desse assunto. Aí eu fui, era uma roda de conversa, elas falaram um pouco das irmãs Mirabal, que lutaram contra a ditadura na República Dominicana, acho que alguma coisa assim. Elas eram da igreja Católica e uniram várias mulheres dentro da igreja para lutar na revolução. E elas [mulheres do coletivo feminista] são apaixonadas pelas irmãs Mirabal, então eu fiquei bem interessada. Só que elas começaram falando mal dos evangélicos, por causa da bancada evangélica e toda a preocupação... e eu fiquei ouvindo. Aí uma senhora do meu lado falou: ah, eu sou de direita e eu vim aqui ouvir um pouco do posicionamento de vocês. E elas: ah, que legal! Obrigada por ter vindo. E aí eu levantei a mão e falei: ah, eu sou evangélica, e eu vim aqui ouvir um pouco do posicionamento de vocês, e eu queria dizer para vocês que a luta das mulheres é uma luta da igreja também, é uma luta de Jesus Cristo, porque ele foi um cara que subverteu tudo, que falou com mulheres que não eram ouvidas, e eu acho que é meu papel ser cristã e estar aqui e andando com vocês. E isso foi a melhor coisa que aconteceu. E no meu primeiro mês de faculdade elas me deram um espaço no jornal para escrever, queriam saber como era ser cristã e lutar pelas mulheres. (Jaqueline)

As identidades evangélica e feminista aparecem em contraste em dois pontos:

1. Pelo argumento exposto de que as mulheres do coletivo começaram a falar mal dos evangélicos, por causa da bancada evangélica que apresenta argumentos contrários a muitas discussões dos movimentos feministas.

O segmento evangélico no Brasil tem passado por um intenso crescimento nas últimas décadas e tem se expressado principalmente pela presença nos meios de 
comunicação e na política institucional. De acordo com Cerveira (2008), além do significativo aumento no número de adeptos, tal grupo religioso tem passado por grandes transformações em sua dinâmica religiosa. Cada vez é maior a diversidade dos que se consideram evangélicos e nota-se uma fragmentação institucional do segmento. É possível observar tanto divergências como convergências entre os grupos que o compõe. Entretanto, por vezes, a identidade reconhecida como evangélica na sociedade brasileira de um modo geral é esta que se relaciona com a bancada evangélica no congresso e por líderes e igrejas que midiaticamente se destacam.

2. A entrevistada cita que o coletivo é um grupo de mulheres socialistas e depois utiliza como exemplo uma mulher de posicionamento político contrário - de direita - que se pronunciou sobre sua presença, inspirando-a a também se pronunciar como evangélica.

Mesmo apresentando as duas identidades aparentemente contraditórias, em seu discurso ela as coloca no mesmo patamar, equiparando a luta do movimento feminista com a luta da igreja em favor da mulher e enfatizando que seu papel como cristã é caminhar junto com as mulheres do coletivo.

Sanchis (2001, p. 27) distingue as posições institucionais, que pretendem ser definidoras de identidade e a comunicação no cotidiano entre os sujeitos portadores das sínteses religiosas que vivenciam por sua própria conta e que podem articular mutuamente dentro de si mesmos, sendo ao mesmo tempo isto e aquilo. As identidades - feminista e evangélica - são colocadas pela estudante como contraditórias. No entanto, estas posições não definem sua identidade por completo, que é formada de uma síntese religiosa construída por ela mesma, a partir de sua vivência como mulher e da experiência religiosa com Jesus Cristo.

Apesar de ter revisto sua própria teoria a respeito da secularização, Berger (2017) afirma que ela não estava totalmente errada. "A modernidade realmente produziu um discurso secular, que permite às pessoas lidar com muitas áreas da vida sem referência a qualquer definição religiosa da realidade” (BERGER, 2017, p. 107). Este discurso existe tanto na mente das pessoas quanto na ordem objetiva da sociedade, onde a maioria das instituições também funciona, ou deveria funcionar, sem qualquer pressuposto de natureza religiosa, como é o caso das universidades não confessionais. 
Isto não significa que todos os discursos religiosos são substituídos pelo discurso secular. Berger (2017, p. 111) observa dois pluralismos: o pluralismo de diferentes opções religiosas coexistindo na mesma sociedade; e o pluralismo do discurso secular e os vários discursos religiosos, também coexistindo na mesma sociedade.

Para a crença dos indivíduos, a implicação disto é simples e extremamente importante. Para a maioria dos crentes religiosos, a fé e a secularidade não são modos mutuamente excludentes de tratar a realidade; não é uma questão de ou/ou, mas antes de tanto/quanto. A capacidade de manipular diferentes discursos (para usar o termo de Alfred Schutz, diferentes estruturas de relevância) é um traço essencial de uma pessoa moderna (BERGER, 2017, p. 111-112).

Na experiência narrada acima constatamos a junção do discurso secular da luta feminista com o discurso religioso que interpreta Jesus como aquele que lutou pelas mulheres. E por isso, os dois discursos não são mutuamente excludentes para esta jovem universitária. Ela se configura com uma pessoa moderna ao manipular estes diferentes discursos para que eles sejam coerentes com as duas identidades que ela assume - evangélica e feminista.

Certamente existem alguns indivíduos que procuram ser totalmente religiosos e outros totalmente seculares. No entanto, "na experiência da maioria dos indivíduos, a secularidade e a religião não são mutuamente contraditórias. De preferência, elas coexistem, cada uma pertencendo a uma forma específica de atenção à realidade” (BERGER, 2017, p. 112), porém, criando pressões entre si, o que faz com que a dúvida seja um elemento sempre presente. "Em termos de religião, o nosso tempo não é tanto uma era da descrença quanto uma era da dúvida. Por isso, a administração da dúvida se torna uma tarefa importante, tanto para os crentes individuais quanto para as instituições religiosas" (BERGER, 2017, p. 131).

\section{CONSIDERAÇÕES FINAIS}

Tendo em vista a experiência relatada pelos universitários participantes da ABUB, podemos dizer de suas trajetórias religiosas que o sentido religioso adquirido anteriormente à sua entrada na universidade se modifica de diferentes formas. Este sentido que antes era fortalecido pelas instituições religiosas, frente ao pluralismo, a 
coexistência de diferentes discursos e compreensões de mundo, pode ser questionado, colocado em xeque pelo contato com o diferente. Crises de sentido podem surgir neste cenário, porém, na busca pela manutenção de sua fé, a ressignificação de alguns pontos de suas crenças e práticas religiosas pode ser uma alternativa para que o sentido religioso permaneça coerente em sua trajetória religiosa.

Pelo percebido nesta pesquisa, podemos identificar pelo menos cinco eixos de ressignificação das crenças e práticas religiosas destes jovens evangélicos universitários. O eixo institucional: jovens que não mais se identificam com a instituição religiosa de origem (ou a questionam) e migram para outra que lhes responda melhor à nova situação ou mesmo criando outra estrutura religiosa; o eixo da afirmação da identidade individual da crença: a nova situação vivida na condição de universitários leva à constituição de convicções religiosas construídas a partir da formatação ou adaptação de sua nova identidade, baseada muito mais em convicções pessoais; o eixo da confrontação com conteúdos da universidade: especialmente nos cursos de ciências humanas, os conteúdos com os quais os estudantes tomam contato levam à ressignificação de suas convicções religiosas tidas como verdadeiras até então; o eixo da influência por convivência neste novo ambiente: a vida em um ambiente diferente e o contato com colegas que cultivam formas comportamentais diferentes daquelas trazidas por jovens evangélicos de suas famílias e igrejas levam a mudanças de práticas que ressignificam sua trajetória religiosa; e por fim o eixo da influência de temáticas transversais que circulam no meio universitário: pautas políticas e sociais debatidas no ambiente universitário e nas quais jovens estudantes evangélicos passam a militar levam também a ressignificações da trajetória de crença.

O processo de ressignificar as crenças e práticas pode levar a movimentos como o trânsito religioso, percurso entre diferentes opções religiosas, as adesões provisórias, a produção de sínteses pessoais para a crença, assim como as negociações próprias em relação às práticas requeridas dos adeptos. $\mathrm{E}$ isto separada ou simultaneamente. 


\section{REFERÊNCIAS}

Aliança Bíblica Universitária do Brasil. Disponível em <www.abub.org.br>. Acesso em: 20 de abril de 2016.

BERGER, Peter. O dossel sagrado: elementos para uma teoria sociológica da religião. São Paulo: Paulus, 2012.

BERGER, Peter. Os múltiplos altares da modernidade: rumo a um paradigma da religião numa época pluralista. Petrópolis: Vozes, 2017.

BERGER, Peter L.; LUCKMANN, Thomas. A construção social da realidade: tratado de sociologia do conhecimento. Petrópolis: Vozes, 2014.

BERGER, Peter L.; LUCKMANN, Thomas. Modernidade, pluralismo e crise de sentidos: a orientação do homem moderno. 3 Ed. Petrópolis: Vozes, 2012.

CERVEIRA, Sandro A. Protestantismo Tupiniquim, Modernidade e Democracia: limites e tensões da (s) identidade (s) evangélica (s) no Brasil contemporâneo. Revista de Estudos da Religião, p. 27-53, mar. 2008.

CHIZZOTI, Antonio. Pesquisa qualitativa em ciências humanas e sociais. Petrópolis: Vozes, 2006.

HERVIEU-LÉGER, Danièle. O peregrino e o convertido: a religião em movimento. Petrópolis: Vozes, 2008.

PIRES, Álvaro P. Amostragem e pesquisa qualitativa: ensaio teórico e metodológico. In: A pesquisa qualitativa: enfoques epistemológicos e metodológicos. Petrópolis: Vozes, 2010, p. 154-211.

PORTELLA, Rodrigo. Religião, Sensibilidades Religiosas e Pós-Modernidade Da ciranda entre religião e secularização. Revista de Estudos da Religião, n.2, p. 71-87, 2006.

RIBEIRO, Jorge Claúdio. Os Universitários e a Transcendência - Visão geral, visão local. Revista de Estudos da Religião, n.2, p.79-119, 2004.

SANCHIS, Pierre. Desencanto e formas contemporâneas do religioso. Ciências Sociais e Religião, Porto Alegre, ano 3, n.3, p. 27-43, 2001.

TAYLOR, Charles. Introdução. In: Uma era secular. São Leopoldo: Ed.Unisinos, 2010, p. 13-37. 